\title{
[FRI0590-HPR] EFFECTS OF SULPHUROUS WATER IMMERSION BATHS IN KNEE OSTEOARTHRITIS PATIENTS: A RANDOMIZED AND CONTROLLED CLINICAL TRIAL
}

\author{
M. Branco 1,2, V. F. M. Trevisani 2,3. ${ }^{1}$ Pontifícia Universidade Catolica de Minas Gerais - PUC MINAS, Poços \\ de Caldas; ${ }^{2}$ Universidade Federal de São Paulo - UNIFESP; ${ }^{3}$ Universidade de Santo Amaro- UNISA, São \\ Paulo, Brazil
}

Background: Osteoarthritis is a degenerative disorder of synovial joints characterized by irreversible loss of articular cartilage and hypertrophic bone changes. As a non-invasive treatment, balneotherapy is used in various rheumatic diseases.

Objectives: Evaluate the effectiveness of immersion baths in sulphurous water in the treatment of knee osteoarthritis.

Methods: A controlled experiment with blind assessment has been conducted. 140 knee osteoarthritis patients of both genders, average age $64.8 \pm 8.9$ years have been selected. These were randomized into three groups: sulphurous thermal water $(n=47)$, non-sulphurous thermal water $(n=50)$, the control group $(C, n=43)$. Patients of sulphurous thermal water and non-sulphurous thermal water groups have been submited to 30 individual treatment sessions, three times a week, lasting twenty minutes each session, for ten weeks. The evaluation took place at three points of time: before the therapy (baseline); after the complete therapy, (endpoint), two months after the Endpoint (follow-up). The considered measures analysed via different questionnaires were as follows: pain (visual analog scale); physical function (WOMAC, Lequesne and HAQ); quality of life (SF - 36) and use of pain medication. The comparisons have been made within and between groups and $p$ values $<0.05$ were considered statistically significant.

Results: The results showed a significant reduction in the levels of pain of the treated groups in comparison to the control group. The sulphurous water group indicated even a greater reduction in pain intensity in comparison to non-sulphurous water group. This significant improvement regarding the analysis of the 3 mentioned groups can be observed in the data base results of the questionnaires WOMAC A, WOMAC B, WOMAC C, HAQ and Lequesne. Parameter quality of life: in both treated groups a significant improvement in all 8 subitems of the SF-36 questionnaires have been observed. When comparing the 3 groups, the treated groups were significantly better than the control group C in all 8 SF-36 subitems. Paramenter use of pain medication: it has been observed that the treated groups made less use of pain medication in comparison to the control group, with statistically significant difference.

Conclusions: Both methods have been effective and have presented better results in comparison to the control group regarding pain reduction, improved physical function, quality of life and reduction on the use of pain medication. Nevertheless the sulphurous thermal water results were superior than the no-sulphurous water ones in the treatment of knee osteoarthritis.

\section{References:}

Esen S, Akararmak, U, Aydan, FY, Unalan, H. Clinical evaluation during the acute exacerbation of knee osteoarthritis: the impact of diagnostic ultrasonography. Rheumatol Int (2013) 33:711-717.

Yurtkuran, M, Yurtkuran, M, Alev, ALP, Nasarcalar, A, Bingol, U, Altan, L, Sarpdere, G. Balneotherapy and tap water therapy in the treatment of knee osteoarthritis. Rheumatol Int, 27:19-27, 2006.

Verhagen, AP, Bierma-Zeinstra, SMA, Cardoso, JR, De Bie, RA; Boers, M; De Vet, HCW. Balneotherapy for Osteoarthritis. A Cochrane Review. J Rheumatol 2008; 35:6.

Acknowledgements: The authors are grateful to Antonio Carlos Thermas in Pocos de Caldas, Minas Gerais for the use of their facilities for conducting this clinical trial.

Disclosure of Interest: None declared

DOI: 10.1136/annrheumdis-2014-eular.1656

Citation: Ann Rheum Dis 2014;73(Suppl2): 1208-1209

Session: Physiotherapy 